\title{
THE IMPACTS OF URBANISATION ON AVIAN COMMUNITIES OF LAHORE
}

\author{
Muhammad Saad Khan* \\ Fatima Javeed** \\ Shama Anbrine***
}

\begin{abstract}
This paper aims to study the impact of infrastructure development on the indigenous avian ecology of a geographic location and focuses on critically observing the role of human interventions in influencing biodiversity within a region. Objectively this research is to identify existing biodiversity of bird species and impacts of urbanisation on the diversity of avian communities in the study areas. For this purpose, this study has examined native avian communities along two Canal areas of Lahore, one being the heavily urbanized Lahore branch of the Upper Bari Doab Canal (popularly known as the Lahore Canal) and the other relatively less populated Ichhogil Canal (popularly known as BambawaliRavi-Bedian or in short BRB Canal). The primary objectives are to study the ecological biodiversity of avian communities in the selected study areas along BRB Canal and Lahore Canal and to highlight the effect of urbanization on the biodiversity of avian species along the selected study areas.
\end{abstract}

Through the above objectives, the study focuses on establishing grounds that bird species which are more adaptable towards an urbanized environment are thriving at the cost of once indigenous and successful bird species. Further, the research also highlights the fact that an insensitive approach towards infrastructure development can destroy the ecology of a region and reduce the variety of avian species that otherwise may thrive in natural habitat.

Keywords: Birds, Lahore Canal, biodiversity, bird communities, urbanisation, Avian communities.

\section{INTRODUCTION}

It is a matter of common observation especially in the case of highly urbanized city centres that along with human beings only a certain type of animals and birds are allowed to co-exist. This situation is intentional as human beings are at the top of the food chain and will not compromise on their comfort, safety, and security. This arrogance on the part of man is destroying the natural ecological balance.

Ecological balance is not only vital for quality of life but also crucial for human survival in an urban area. One of the major problems of $21^{\text {st }}$ century is that urban areas are becoming dominantly human (Karieva et.al, 2007) at the cost of other living species. Consequently, there are many incidents where man has threatened and sometimes caused the extinction of different species. Human activities such as deforestation, desertification, pollution and urban sprawl which severely disturb ecological systems are considered to be the driving forces behind the extinction of species (Purvis, et.al., 2000). According to World Wild Life Fund (WWF, 2016), habitat loss poses the greatest threat to species. The world's habitats like forests, swamps, plains, lakes are diminishing and humans are populating and developing these habitats to cater for their needs. Agriculture, housing, roads, pipelines and the other hallmarks of industrial development totally change the ecology of such habitats. Important ecological habitats will continue to disappear if a strong plan is not created to protect sensitive areas. It is estimated that over the next half of a century, up to onethird of the world's plant and animal species may be lost forever. Conservation biologists regard this as the first mass extinction since the age of the dinosaurs (Ewing et.al, 2005).

Bird extinction' has been 'tied to the arrival of humans as 'Moa', a native flightless bird of New Zealand became extinct within a century of the arrival of human settlers in the region (Numer, 2014). Similarly, the documentation of another bird specie Dodo's extinction suggests overhunting by humans as the main cause of its disappearance (Freedman, 1995). Correspondingly there are many disaster zones which have been evacuated by humans, and have become accidental natural reserves. For instance in Chernobyl, European grey

\footnotetext{
* Muhammad Saad Khan, Assistant Professor, Department of Architecture, UET, Lahore.

** Fatima Javeed, Assistant Professor, Department of Architecture, UET, Lahore.

*** Dr. Shama Anbrine, Assistant Professor, Department of Architecture, UET, Lahore.
} 
wolf species have thrived as humans abandoned this area due to radiation hazards (Wendle, 2015). The survival of Chernobyl European grey wolf proves that human presence or urbanization is more risky and fatal to many species than other hazards and disasters.

Urbanization and urban sprawl are primarily aimed at providing modern human centric comforts. However, these modern comforts are accompanied by the destabilization of the ecological cycle. This is a general condition worldwide in all urban areas and Lahore, the case study, is no exception. Being the capital of Punjab as well as the second largest metropolitan area in the country, Lahore has undergone expansion at an exponential rate during the last two decades. In Lahore, one major drawback is that because of this expansion the agricultural land at the periphery of the city is being used as satellite residential towns. This agricultural land used to be the food provider for the entire city and the surrounding areas and was a habitat for many natural bird and animal species. Subsequently, these satellite towns have reduced the open green areas and fields of the city in a vain pursuit to provide better housing and subsequently more residential areas to shelter the swelling human population.

Historically Lahore has been rendered and celebrated as a 'City of Gardens'. The Mughal Royal gardens and peripheral landscapes have been a quasi-essential part of the city, to the extent that these served as a source of inspiration for the western colonizers. Thus, tradition was kept alive in the British era and new gardens and parks were added to the urban morphology of Lahore. After independence, some gardens were also planned but unfortunately the rate of extinction of older gardens was higher than the addition of new ones. Hence the environmental degradation became a prominent characteristic of the city with increased level of pollutants and diminished open green areas.

Thus, it is intended through this research to understand how to mitigate the negative impacts of current urban sprawl trends in Lahore. The new residential societies are changing the current ecological balance of the city and eventually may lead to the point from where it is impossible to return. Thus the need for this research was felt to identify ecologically biodiverse avain communities and the impact of urbanization on them.

\section{LITERATURE REVIEW}

The ecological impacts of growth in human population and its re-distribution towards urban hubs are substantial. The loss of green areas including wild lands, forests and agricultural lands to urban sprawl affects local climate and air quality. This alteration in climate changes the energy dynamics which leads to decreased native biodiversity (Vitousek et al., 1997; Grimm et al., 2000; Alberti et al, 2003; Dudgeon et al, 2006). Running waters integrate the effects of land-use change and are very sensitive to urbanization. As soft land is replaced with a large amount of impervious surface such as asphalt, concrete, and rooftops, the hydrology and geomorphology of streams receiving runoff water are fundamentally altered which can possibly cause severe results. (Wolman, 1967; Walsh, 2000; Paul and Meyer, 2001). Therefore, when streams and water channels become infected with hazardous pollutants the urban river transforms from a functioning ecosystem to a filthy sewer.

Many types of researches undertaken by various scholars have duly established and emphasised the role of green spaces in an urban setting. Significant research in the 1980s and 1990s brought strong support to the statement that 'condition of natural has significant positive influences on health outcomes of all species within an ecosystem'. (Ulrich 1981, 1984, 1992; Hartig et.al, 1991). These positive influences are both physical and psychological as demonstrated by Francis et. al, 1990. This study analysed peoples' preference of spaces during the time of distress and pain and concluded that the majority chose to go outdoors to a natural or designed setting (Francis and Cooper, 1991, 1992). Hence, green spaces are a crucial part of any social environment as these have a strong role to play in the welfare of a society.

Similarly, when parks were first designed in the $19^{\text {th }}$ century, city officials had a strong belief in the possible health advantages that would offer (Maller et al., 2005). It was hoped that parks would reduce disease, crime, and social unrest as well as provide 'green lungs' for the city, and areas for recreation (Maller et al., 2005). These assumptions were used as justification for providing parks and other natural areas in cities, and preserving wilderness areas outside of cities for public use (Maller et al., 2005).

Hence green spaces which incorporate eco-balance strategies are not only beneficial for the humans but also aid biodiversity within an urban area. These spaces are also considered lungs of any city which purify the rest of the city. Once the City of Gardens - Lahore, still had some green pockets but the urban growth in Lahore has severely affected its natural ecology. There have been some studies that document the facts that Lahore's ecology has changed over the years. Following section looks at the researches carried out on birds of Lahore in its different green pockets and areas. 


\section{PREVIOUS ECOLOGICAL STUDIES IN LAHORE}

Development in the city took its toll when modern infrastructure replaced many indigenous trees which resulted in the destruction of the habitat of birds such as the YellowFooted Green pigeon, Grey Hornbill, Alexandrine Parakeet, etc. Only a few small pockets were left in the city of Lahore that housed indigenous trees. Ultimately, this resulted in confinement of bird populations to these disjointed patches within the city (Masood, 2014).

The impact of urbanisation on bird's population and diversity was evident in another similar study. This research was carried out in monsoon and winter seasons and the researcher prepared feeding station points to observe and count the bird species in different areas of the city of Lahore. The number and variety of birds were documented from dawn to dusk to note the bird's urbanization in the area. The result showed that the avian population was season dependent. One interesting conclusion was that mainly sparrow and pigeon population were observed in densely populated areas. On the other hand, areas that had more vegetation showed diversity in bird species. In this study 49 species of birds were observed in Lahore, Nishtar Town had the highest number of bird species whereas, 41 species were observed in Wagah Town. Shalimar Town and Ravi Town were most congested and home for only two to three species (Joshua and Ali, 2011).

One study documented the Ravi River near Lahore and five sites were studied from mid-March to mid-September in 2008. There were 22 species of birds and bird diversity was dependent on the environment quality (Iqbal et al., 2011). Even though River Ravi, once reflected the green Lahore, now it has become so polluted that the bird diversity is declining.

Passerine bird species in Lahore is higher in old green sites with native trees than in new parks of Lahore. Human disturbance and non-availability of breeding sites in new parks are the main reason behind the loss of Passerine Avian diversity. New parks have more decorative or ornamental plants that don't provide enough shelter to the birds. Similarly, Wildlife Park outside Lahore is more close to nature, with less human intervention, and it houses more diverse bird population than any other new park (Fazal et al., 2014).

Many types of research, as discussed above, have already been conducted to document the fact that high pollution in densely populated areas adversely affects the environment and hence the bird species. With city growth, a major concern is usually traffic that has harmful effects on the environment. Big cities, increased wealth, and population growth are directly related to increased use of vehicles. These vehicles use fuel which is a serious cause of concern as lead and nitrogen peroxide are released into the environment (Suk et al., 2003). These pollutants are hazardous for birds and for the overall ecosystem. Moreover, there is a direct link of urban congestion with overall pollution in the city. More congested spots in Lahore show higher level of pollution (Aziz and Bajwa, 2004). Congestion also causes higher level of noise pollution as well according to a study carried out in 2011 congested areas had higher noise levels (Younes and Ghaffar, 2012). Different pollution types are harmful to humans and similarly, congested areas have fewer bird species that survive urban growth (Joshua and Ali, 2011).

Lahore's environment has already deteriorated because of unplanned urban growth. There have been many surveys to document the air quality in major cities of Pakistan but these surveys only give a general idea about pollution statistics. A true picture can only be drawn after obtaining data from long-term monitoring programs (Aziz, 2006). In 2000, a survey was conducted which showed a high concentration of pollutants in the country. Survey was carried out in a joint effort with the Japan International Cooperation Agency and Pakistan Environmental Protection Agency. World Health Organizations (WHO) database for the year 2008-2013 shows that generally pollution has doubled and Pakistan falls in the region where pollution is 5-10 times higher than WHO's limit (WHO, 2015a). In general, over the years, Lahore's pollution has been increasing and it is ranked as the tenth most polluted city in the world, and Pakistan takes the position of the third most polluted country according to WHO's recent database of outdoor air pollution in cities (WHO, 2015a). All these recent reports on the environment of Lahore unmistakably point to the fact that the city has become hazardous for birds and other life forms. However, pollution is considered as one of the main factors but bird species are also threatened by agriculture, recreation, and many other human impacts (Mckinney, 2006).

Different researches document the fact that bird diversity is dependent on environmental quality, native trees for necessary activities and more open areas. This paper aims to go one step further and compare two sites which are similar but mainly affected by human disturbance because of higher population and presence of infrastructure. Both canals add to green pockets of Lahore but human intervention level is different as their surroundings are urbanized at different levels. 


\section{RESEARCH METHODOLOGY AND DATA COLLECTION}

For the two canals of Lahore selected for comparison, data was collected by visiting the sites repeatedly (Figure 1) and using observation as the key data collection technique. The observations are quantified in tabular form in the results to conclude the study.

The study area has been limited to a distance of approximately 2 kilometers along the banks of both the canals. In the case of the Lahore Canal, the study area stretches from the junction of Ferozpur Road and Canal Road to the junction of Jail Road and Canal Road (Figure 2). On the other hand, BRB Canal study area stretches from Barki Road junction to Bedian Road junction (Figure 3).

This data was collected by using reconnaissance surveys. These surveys were conducted in the months of December and January 2013 between $12 \mathrm{pm}$ to $3 \mathrm{pm}$ local time. The methodology adopted for the surveys was based upon point count and area searches. There were point count stations and casual walks in between the stops. A total of eight stops of approximately ten minutes each on both study areas were carried out to silently observe and document the visible bird species. The survey team was advised to wear earthen colors which would blend in with the surroundings. The observations from these surveys were documented as photographs for the identification of bird species living in the area. This resulted in the generation of quantitative data about the natural ecology of the research sites.

Here, it is important to mention that although methods of area searches and point count are standard for monitoring birds but the extent of this paper is just to compare the difference between two sites and not to extend the scope of research in studying or analyzing behavioral patterns of birds in any form.

\section{RESEARCH SITES}

Lahore, one of the major cities of Punjab, is diverse in climatic conditions. It offers all four seasons to different species. The two selected canals offer different types of environment to the bird species. Lahore Canal is heavily urbanized whereas BRB offers a rural setting for different species.

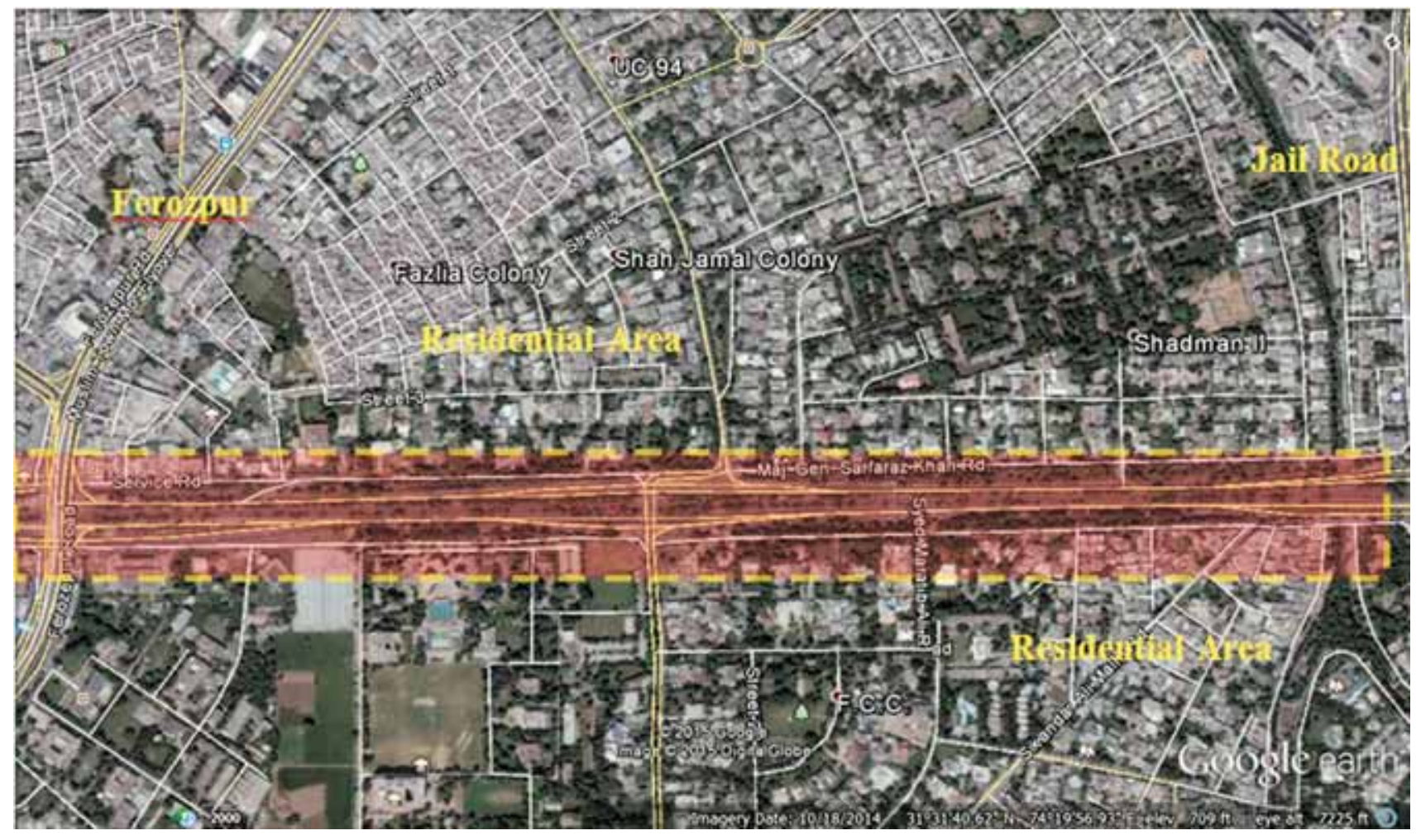

Figure 1: Study area around the Lahore Canal 


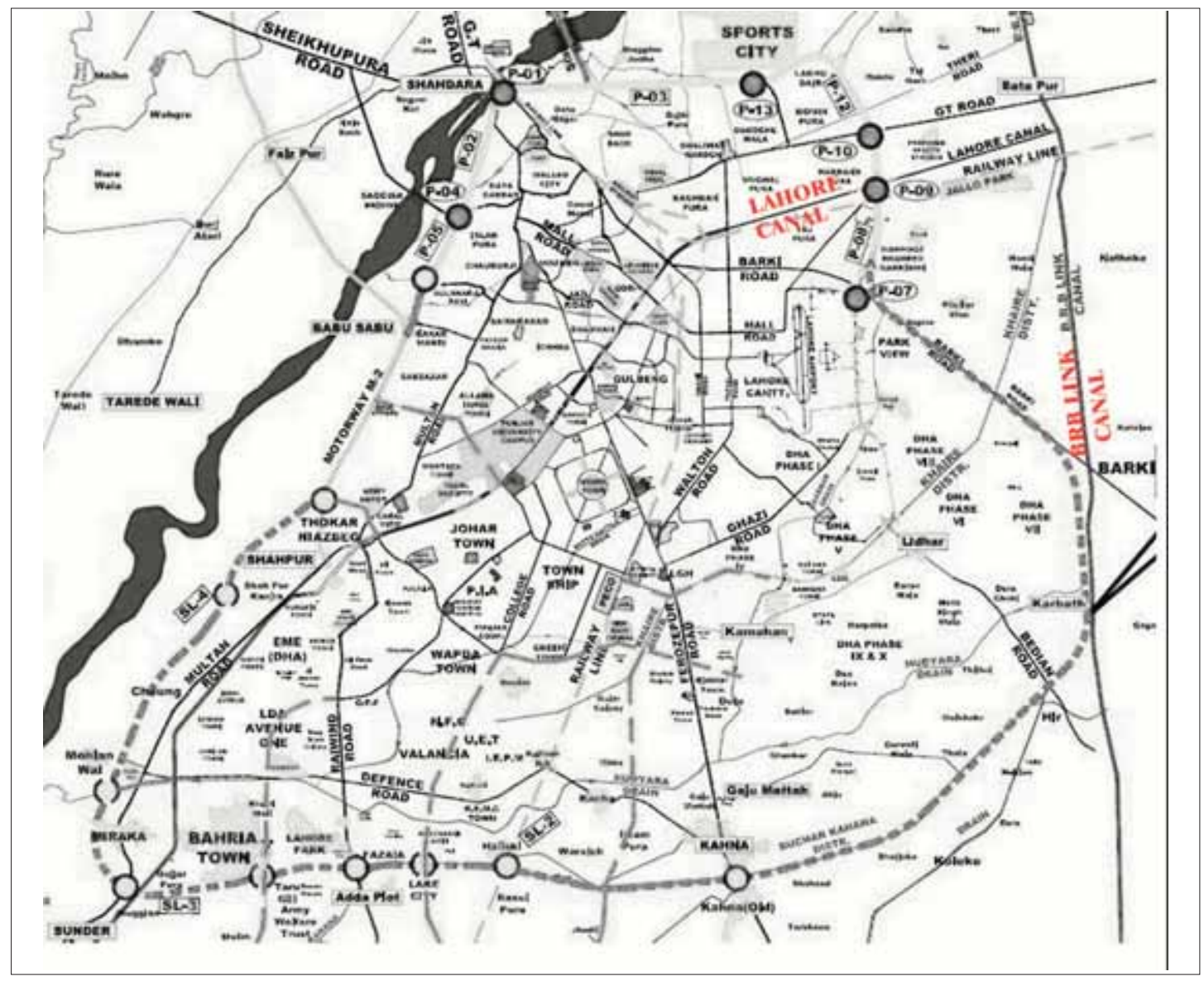

Figure 2: Map of Lahore showing the Lahore Canal and BRB Canal

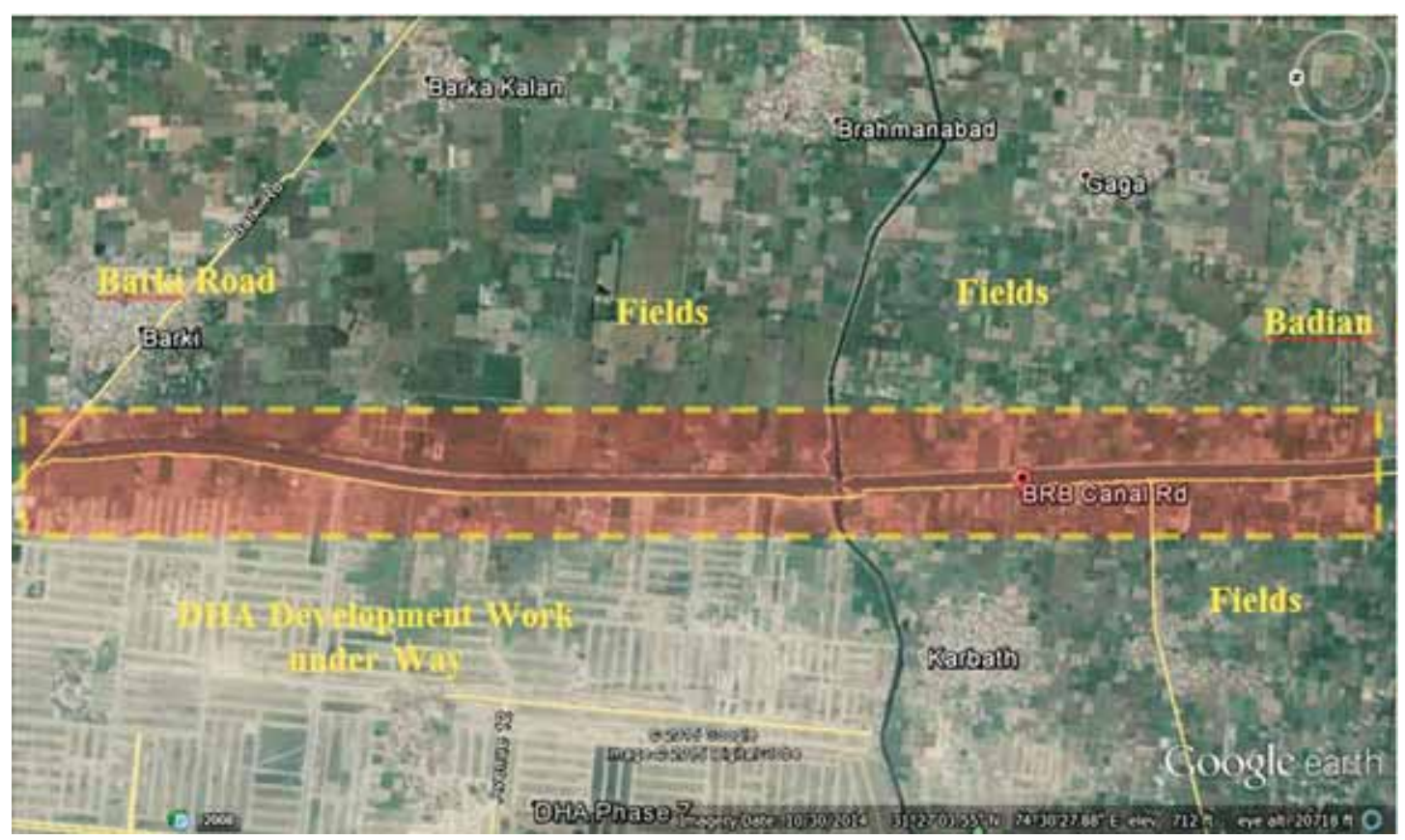

Figure 3: Study area around BRB Canal 
Lahore Canal has been the principal Canal in the Lahore division since Mughal times. During the British times, it was expanded in 1861 and it ran down the central spine of the district traversing through Gurdaspur, Amritsar and Lahore districts. According to the Gazetteer of Lahore district 1883-4 'The main line of this Canal enters the Lahore district near Badhana and runs down to Wan Khara, in the Chunian tehsil, whence a permanent escape had been dug to the river Ravi at Alpa. The Lahore branch of the same Canal enters at Wahgah passes between Lahore and Meean Meer (presently Lahore Cantonment) and joins the river Ravi at Niaz Beg, a large village eight miles south-west of Lahore. Its length is 59.5 miles' (Walker, 1989:62) (Figure 4).

Today it is flanked on both sides by the Canal Bank Road, a six-lane two-way road being one of the largest and the busiest roads of Lahore (Figure 5). This road is a prime connection to numerous high profile residential, commercial and educational areas on both sides of the Canal as well as the shortest route to the outer periphery of the city by the virtue of offering signal-free lanes. Hence the surroundings of Lahore Canal have been affected severely by intensive human interventions, both in the form of building construction and the pollution resulting from heavy vehicular traffic.

BRB Canal is 45 miles long Canal running on the eastern boundary of Lahore. It was a public venture built by the residents of Lahore in 1948 as a strong defensive measure to ensure the safety of Lahore (Singh, 2000) at the request of the (then) Chief Minister of West Punjab, Nawab Iftikhar Hussain Khan Mamdot. It is located in a very low populated area and flanked by vast green fields on the periphery (Figure $6)$.

The study area has been limited to a distance of approximately 2 kilometres along the banks of both the Canals.

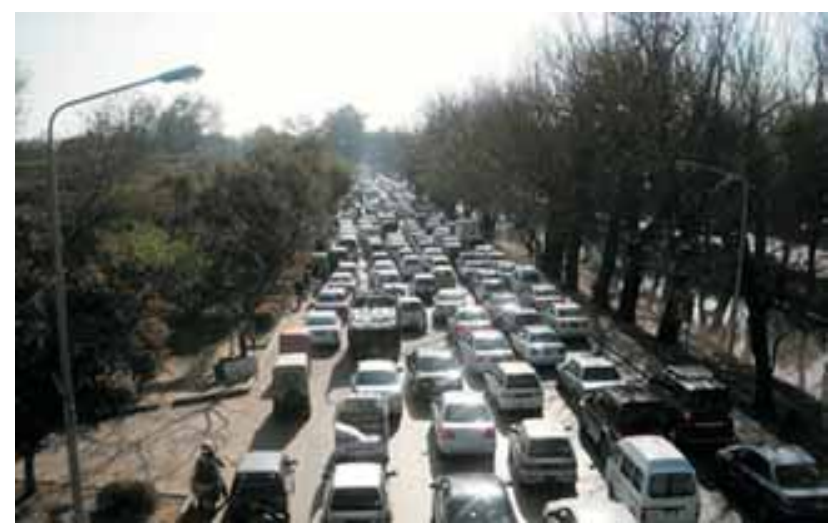

Figure 5: Lahore Canal

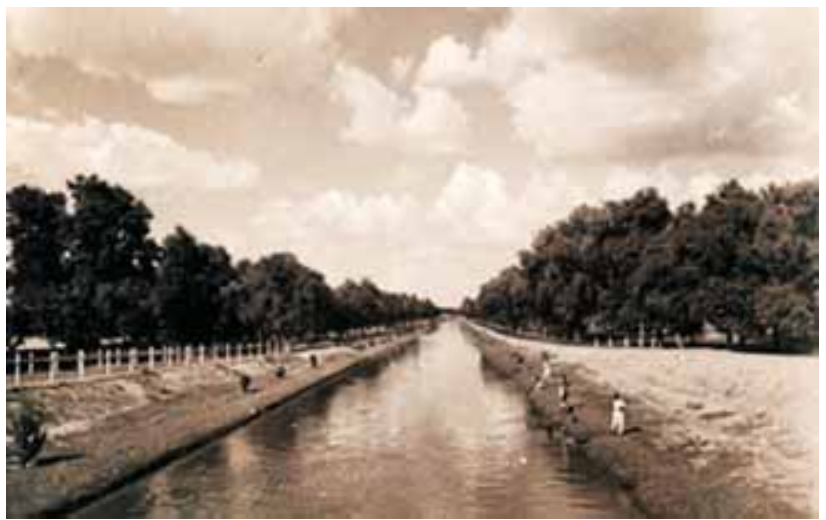

Figure 4: Lahore Canal in 1915

Source: Walker, 1989

\section{RESULTS}

The tables show various bird species which were observed in the selected locations on both the canals. A simple assigned numeric value system was adopted to assess the relativity of biodiversity amongst the selected locations. Following assigned value system has been used:

$0=$ NIL (for birds that are completely not found in the specific area during study time*)

$1=$ MIN (for birds that have been seen less than 5 times in the specific area during study time*)

$2=\operatorname{MAX}$ (for birds that have been seen more than 5 times in the specific area during study time*)

* Study time: 11 am to $3 \mathrm{pm}$

A total of twenty five different bird species were identified

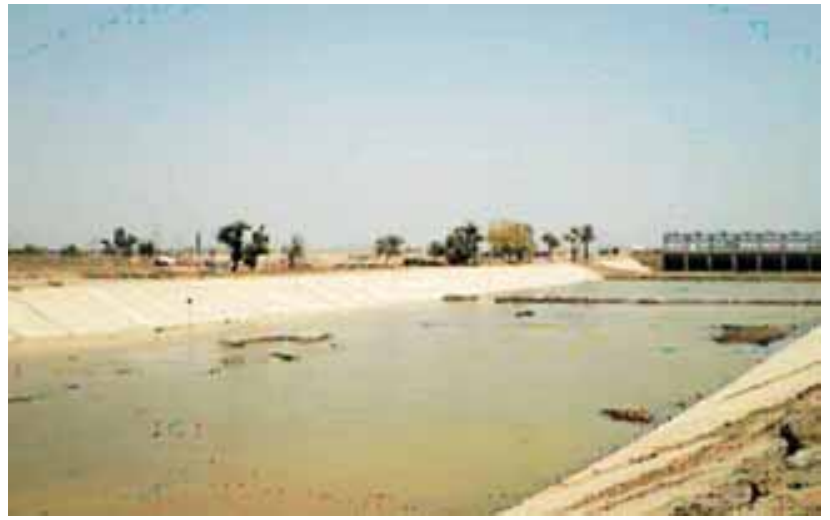

Figure 6: BRB Canal Lahore 
at the two sites as indicated in Table-1. This data clearly shows that there is a huge differential in the overall ecological biodiversity of birds of the two study areas. All twenty-five bird species were observed at the BRB Canal site while sixteen different bird species were identified at the Lahore Canal site. This shows that nine more bird species are living on the BRB Canal.

The table also evidently shows that BRB Canal has a biodiverse avian population which is thriving due to minimum human intervention with respect to infrastructure development and availability of natural habitat for the birds, while the Lahore Canal loses out with a lesser bio-diverse avian population due to loss of natural habitat, pollution, and noise levels.
Further, the research clearly shows that avian population at the study area of BRB Canal is much higher than the avian population at the Lahore Canal. For example, the numbers of dove sighting at the BRB Canal were much higher than the Lahore Canal sightings. The study proves that BRB Canal has better avian biodiversity and population numbers.

\section{CONCLUSION AND RECOMMENDATIONS}

The aim of this study was to understand that how the natural ecology of two very similar features can differ because of their immediate context. Lahore Canal is highly urbanized with modern infrastructure development, on the other hand, the BRB Canal as a whole still remains secluded and lacks modern infrastructure.

Table-1: Ecological Biodiversity Assessment Table for Bird Species

\begin{tabular}{|c|c|c|c|c|c|c|}
\hline \multicolumn{3}{|c|}{ SIGHTED BIRDS } & \multicolumn{2}{|c|}{ BRB CANAL } & \multicolumn{2}{|c|}{$\begin{array}{l}\text { LAHORE } \\
\text { CANAL }\end{array}$} \\
\hline No. & Name of Bird & $\begin{array}{l}\text { Local } \\
\text { Name }\end{array}$ & Quantity & Value & Quantity & Value \\
\hline 1. & Black Neck Dove & Fakhta & Max & 2 & Min & 1 \\
\hline 2. & Red Turtle Dove & Ghugi & Min & 1 & Max & 2 \\
\hline 3. & Wood Pigeon & $\begin{array}{l}\text { Jungly } \\
\text { Kabootar }\end{array}$ & Min & 1 & Max & 2 \\
\hline 4. & $\begin{array}{l}\text { Yellow-footed Green } \\
\text { Pigeon }\end{array}$ & Hurryal & Min & 1 & Nil & 0 \\
\hline 5. & Water Hen & Jul-Kukni & $\operatorname{Max}$ & 2 & Nil & 0 \\
\hline 6. & Moorhen & Pandopi & Max & 2 & Nป & 0 \\
\hline 7. & Duck & Murghabi & Min & 1 & Nil & 0 \\
\hline 8. & Crow & Kawa & Max & 2 & Max & 2 \\
\hline 9. & Eagle & Cheel & $\mathrm{Min}$ & 1 & Max & 2 \\
\hline 10. & Sparrow & Chirdia & Min & 1 & Max & 2 \\
\hline 11. & Egret & Bagla & Max & 2 & Nil & 0 \\
\hline 12. & Snipes & - & Max & 2 & Nil & 0 \\
\hline 13. & Red Wattled Lapwing & Tateree & Max & 2 & Nil & 0 \\
\hline 14. & Humming Bird & - & Max & 2 & Min & 1 \\
\hline 15. & Spotted Staring & Tilyar & Min & 1 & Nil & 0 \\
\hline 16. & Myna & Mena & Max & 2 & Max & 2 \\
\hline 17. & Wood Pecker & Hud hud & Max & 2 & Max & 2 \\
\hline 18. & King Fisher & - & $\operatorname{Max}$ & 2 & Min & 1 \\
\hline 19. & Nightengale & Bulbul & $\operatorname{Max}$ & 2 & Max & 2 \\
\hline 20. & Crow Pheasant & - & Max & 2 & Nil & 0 \\
\hline 21. & Cuckoo & Koel & $\operatorname{Max}$ & 2 & Min & 1 \\
\hline 22. & Indian Robin & - & Max & 2 & Min & 1 \\
\hline 23. & Indian Parrot & Tota & Min & 1 & Min & 1 \\
\hline 24. & Babbler & Lutera & $\operatorname{Max}$ & 2 & Min & 1 \\
\hline 25. & Grey hombill & - & Min & 1 & Min & 1 \\
\hline \multicolumn{3}{|c|}{ Total Value } & \multicolumn{2}{|c|}{41} & \multicolumn{2}{|l|}{24} \\
\hline
\end{tabular}


In context of the city of Lahore, the research shows that two very similar features hardly ten kilometres apart from each other can have exponentially different avian communities. Excessive and insensitive human intervention in terms of population, infrastructure and pollution are the primary factors that differentiate the two sites. Here it is important to note that Lahore Canal makes the spine of city and roads on both sides of the Lahore Canal are heavily used throughout the day, while BRB Canal is located on the outskirts of Lahore away from the population. The chart in (Figure 7) evidently shows that BRB Canal has much more bio-diverse avian population. Bird species are thriving near BRB Canal due to minimum human intervention with respect to infrastructure development and availability of natural habitat for the birds, while the Lahore Canal loses out with a lesser bio-diverse avian population due to loss of natural habitat, pollution and noise levels.

Another interesting phenomenon, which can be observed from Figure 7, is that certain species of birds are thriving along the Lahore Canal which includes Red Turtle Dove, Wood Pigeon, Crow, Sparrow, Eagle, Mayna, Wood Pecker and Nightingale. On the other hand, BRB Canal, though more bio-diverse and having good population numbers, has a lesser population of Red Turtle Dove, Wood Pigeon, Eagle, and Sparrow. This proves that these bird species are more adaptable to an urban environment and have evolved as opportunists. Their nutrition is mostly dependent on waste material generated by an urban environment. Most of these birds find shelter in man-made infrastructure and are not shy of human beings.

Based on the findings of this research, it can be concluded that avian ecology and biodiversity are diminishing rapidly at the Lahore Canal primarily due to its surrounding urban context. WWF (2016) has also documented this fact and has found that indigenous trees were cut down in the name of development and need of new bridges, underpasses and widening of the roads. This ultimately destroyed the habitat of birds such as Yellow-Footed Green Pigeon, Grey Hornbill, Alexandrine Parakeet. The large indigenous trees were restricted and confined to only a few small pockets which gave shelter to bird population and resulted in fragmented habitats for birds. The new and exotic varieties of trees planted to replace indigenous trees changed the horticulture pattern of flora in Lahore and took away the nesting shelters of birds.

Though this research indicates a flourishing bird ecology at the BRB Canal, the worrying part of this study is that the natural ecology and biodiversity which to date remains healthy, is threatened by development work being carried out by Defence Housing Authority (DHA) along the canal side. The point of concern is the new residential societies being developed along Barki Road that cross BRB Canal. The direction of growth is alarming as DHA Lahore has

\section{Comparative Study Chart for Avian Communities Along BRR/ Lahore Canal}

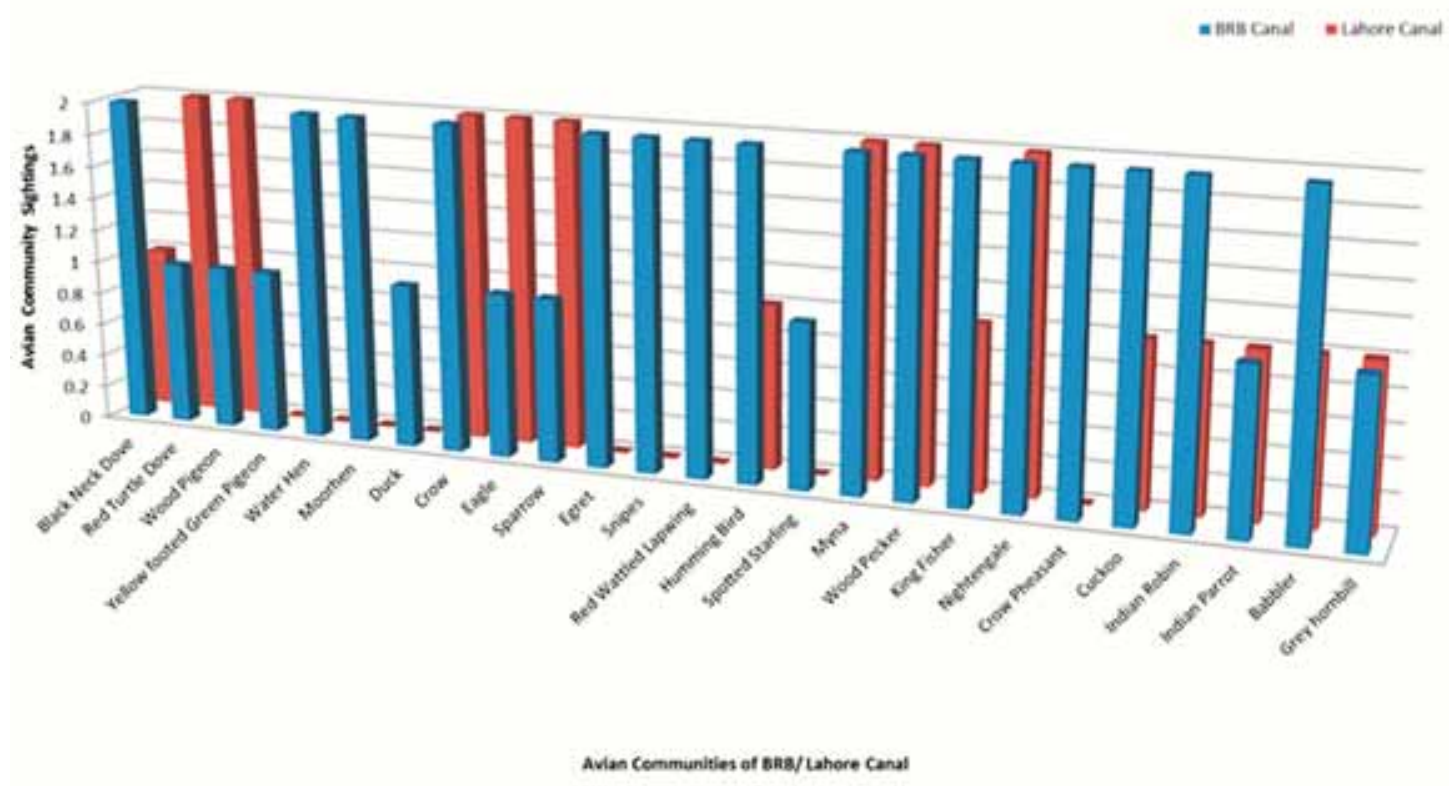

Figure 7: Chart showing comparison of birds diversity in BRB Canal and Lahore Canal 
already reached BRB Canal and its flora and fauna will be affected once residents start occupying the land near BRB.

Initially, urbanization may appear harmless as humans and birds can live in harmony but analysis of current bird pattern near human population and in areas away from human population shows different results. By creating new towns, the construction industry is turning the ecological system of the city of Lahore upside down. While the developers claim that their proposed construction has a minimum intervention on the natural and ecological reserves as they provide public parks, green spaces, and farmhouses within the town limits, but in reality these interventions result in serious ecological imbalances within the area. This is because naturally sustained and organically developed green spaces have a different impact on ecology as compared to reserved grasslands that become part of an urban sprawl. Urban growth also increases air and noise pollution because of heavy traffic and modern living style. This leads to further deterioration of green spaces and can lead to extinction of certain bird species.

There is a dire need to create an understanding about the rapid rate at which the landscapes and critical ecosystems that support a vast range of wildlife are being lost. This is ultimately a great loss for the entire human race. Hence there is a desperate need to strive towards the maintenance of ecological balance by implanting natural reserve areas within the urban limits of all major cities. Disturbances in ecological balance threaten plants, birds, animals and consequently humans towards extinction. Hence the ecological depletion of non-human species is alarming and again requires immediate thought and action.

\section{REFERENCES}

Alberti, M., Marzluff, J. M., et al., 2003, 'Integrating humans into ecology: Opportunities and challenges for studying urban ecosystems’, Bio Science, 53(12), 1169-1179.

Aziz, J.A.,2006, 'Towards establishing air quality guidelines for Pakistan', Eastern Mediterranean Health Journal, 12(6), 886-893.

Aziz, A. and Bajwa, I. U., 2004, 'Energy and pollution control opportunities for Lahore', Urban Transport X, 751-760.

Dudgeon, D., Arthington, A.H. et al., 2006, 'Freshwater biodiversity: importance, threats, status and conservation challenges', Biological Reviews, 81(2), 163-182.

Ewing, R., Chen, J. K. et al., 2005, Endangered by sprawl: How runaway, National Wildlife Federation, Smart Growth America and Nature Reserve, Washington, D.C.

Fazal, S., Ali, Z. et al., 2014, 'A study on the avian (passerine) diversity of Lahore', The Journal of Animal and Plant Sciences, 24(4), 1270-1275.

Francis, C. and Cooper, C. M., 1992, 'Restorative places: Environment and emotional well-being', $24^{\text {th }}$ Annual Environmental Design Research Association Conference, Boulder.

Francis, C. and Cooper, C. M., 1991, 'Places people take their problems', $22^{\text {nd }}$ Annual Conference of the Environmental, Oklahoma City.

Freedman, B., 1995, Environmental ecology: The ecological effects of pollution, disturbance, and other stresses, Academic Press, London.

Grimm, N., Morgan, B. et al., 2000, 'Integrated approaches to long-term studies of urban ecological systems', BioScience, 50(7), 571-84.

Hartig, T., Mang, M. et al., 1991, 'Restorative effects of natural environment experiences', Environment and Behavior, 23(1), 3-36.

Iqbal, M., Saleem, I. et al., 2011, 'Bird ecology from the Ravi River of Lahore: Habitat degradation', The Journal of Animal and Plant Sciences, 21(4), 817-821.

Joshua, G. and Ali, Z., 2011, 'Avian diversity with the varying urban congestions of Lahore', The Journal of Animal and Plant Sciences, 21(2), 421-42. 
Kareiva, P., Watts, S. et al, 2007, 'Domesticated nature: shaping landscapes and ecosystems for human welfare' Science, 316(5833), 1866-1869.

Maller, C., Townsend, M. et al., 2005, 'Healthy nature healthy people: 'contact with nature' as an upstream health promotion intervention for populations', Health Promotion International, 21(1), 45-54.

Masood, N., 2014, 'Ecological linkages of some sedentary bird species in selected urban habitats of Lahore', Masters Thesis, Kinnaird College for Women Lahore, Lahore.

McKinney, M.L., 2006 'Urbanization as a major cause of biotic homogenization', Biological Conservation, 127(3), 247260.

Numer, R., 2014, 'Bird's extinction is tied to the arrival of humans', The New York Times, March, D5.

19. Paul, M. J. and Meyer, J. L., 2001, 'Streams in the urban landscape', Annual Review of Ecology and Systematics, 32, 333-365.

Purvis, A., Gittleman, J. L. et al., 2000, 'Predicting extinction risk in declining species', Proceedings of Royal Society Conference of Biological Sciences, 267(1456), 947-1952.

Singh, J., 2000, With honour and glory: Wars fought by India 1947-1999, Lancer Publishers, New Delhi.

Suk, W. A., Ruchirawat, K. M., et al., 2003, 'Children health: Environmental threats to children's health in Southeast Asia and the Western Pacific', Environmental Health Perspectives, 111(10), 1340-1347.

Ulrich, R. S., 1981, 'Natural versus urban scenes: Some psychophysiological effects', Environment and Behavior, 13(5), 523-556.

Ulrich, R. S., 1984, 'View through a window may influence recovery from surgery', Science, 224(4647), 420-421.

Ulrich, R. S., 1992, 'Effects of interior design on wellness: Theory and recent scientific research', Journal of Healthcare Design, 3, 97-109.

Vitousek, P. M., Mooney, H. A. et al., 1997, 'Human domination of earth's ecosystems', Science, 277(5325), $494-499$.

Walker, G. C., 1989, Gazetteer of the Lahore District: 1883-4, Sang-e-Meel Publications, Lahore.

Walsh, C. J., 2000, 'Urban impacts on the ecology of receiving waters: a framework for assessment, conservation and restoration', Hydrobiologia, 431(2), 107-114.

Wendle, J., 2015, Chernobyl and other places where animals thrive without people, viewed 2 September 2014, from http://news.nationalgeographic.com/2015/10/151008-chernobyl-animals-thrive-without-people-science/.

WHO, 2015, Air pollution levels rising in many of the world's poorest cities, viewed 25 July 2014, from http://www.who.int/mediacentre/news/releases/2016/air-pollution-rising/en/.

WHO, 2015a, Public health, environmental and social determinants of health (PHE), viewed 21 July 2014, from http://www.who.int/phe/health_topics/outdoorair/databases/cities-2011/en/.

Wolman, M. G., 1967, 'A cycle of sedimentation and erosion in urban channels', Geography Annals, 49(2), 385-395.

WWF, 2016, World Wildlife Fund, viewed 22 March 2014, from http://www.worldwildlife.org/.

Younes, I. and Ghaffar, A., 2012, 'Spatial pattern of noise pollution in Lahore city 2011', Asian Journal of Social Sciences and Humanities, 1(2), 53-60. 